\title{
The Social Support Network of "Ant Tribe" in Beijing
}

\author{
Yan Rong ${ }^{1}$, Sha $\mathrm{Cui}^{2} \&$ Jaiwei Chen ${ }^{3, *}$ \\ ${ }^{1}$ School of Economics and Management, Tsinghua University, Beijing, P. R. China \\ ${ }^{2}$ Department of Information Management, Peking University, Beijing, P. R. China \\ ${ }^{3}$ School of Systems Science, Beijing Normal University, Beijing, P. R. China \\ *Correspondence: School of Systems Science, Beijing Normal University, Beijing, P. R. China. E-mail: \\ chenjiawei@bnu.edu.cn
}

Received: March 19, 2016 Accepted: April 11, 2016 Online Published: May 8, 2016

doi:10.5430/sass.v3n2p9 URL: http://dx.doi.org/10.5430/sass.v3n2p9

\begin{abstract}
"Ant tribe" is a unique group emerges during social transition in China. Due to their large quantity, poor living condition and high education level, more and more attention has been paid to them by policy makers and researchers. In the current study, we analyzed the characteristics of their social support network based on a network survey on "ant tribe" in Xiaoyuehe district, Beijing. We found that the social network connectivity of "ant tribe" was weak; the network structure was unstable; some key persons had salient and dominant influence in social interaction; a lot of components existed in the network. Implications for policy makers and other vulnerable groups are discussed.
\end{abstract}

Keywords: ant tribe; social support network; giant component; social network analysis

\section{Introduction}

China has being experiencing urbanization, population structure change, labor market restructuring, high-education expansion and a series of structural reforms. Their combined effects lead to a growing number of "ant tribe" (Y. He \& Mai, 2015; Lian, 2009, 2011). They are university graduates with low-income and poor living condition in big cities such as Beijing, Shanghai and Guangzhou. Just like "ants", they are intelligent, hard-working, while underpaid. Lian (2009) described this group as "clever, weak and living as a group". They are "clever" as "ant tribe" consists of young college graduates (S. Ren, Zhu, \& Warner, 2011). They are "weak" as many "ants" come from less developed regions in China, and lack social and financial capital to compete in job market (Han, 2011). Due to low social class and income, their social relationship is marginalized by mainstream of the society (Han, 2011). In order to save rent, the "ants" have to live in poverty-level places characterized by one or more of the following attributes: group rental, shared public place such as kitchen and bathroom, 8 or more bunks in a small room, distant from city center, and poor infrastructure in community (J. k. Zhang, Wang, \& Wu, 2012). The Annual Report on the Labor Market of China (2010) pointed out that, the quantity of "ant tribe" is more than 100000 in Beijing (Pan, 2010). In 2013, the total number of "ant tribe" in China is more than 3 million, and is growing rapidly by $0.2-0.3$ million per year (X. Zhang, 2013).

However, previous studies on "ant tribe" only focused on descriptive analysis such as their demographic characteristics or basic living status (Gu \& Sheng, 2012; Lian, 2009). For example, Chan and Lu (2011) explained the emergence of "ant tribe". X. Zhang (2013) described the living condition and psychological status of "ant tribe". While the social support network of this group are yet to be investigated. To improve their status quo and help them integrate into society not only requires individual effort, but also social support. Social support refers to various forms of aids and assistance offered by friends, family members, colleagues and others (Wright et al., 2013). At micro level, social support is a moderator of life stress and crisis (Wright et al., 2013), and contributes to both mental and physical health (Z. P. He, 2011). At macro level, social support network helps increase social connectivity and reduce the social conflicts thus enables social stability (Z. P. He, 2011). As a result, understanding the structure of social support network has became a hot topic with intense theoretical and practical interest (Gottlieb \& Bergen, 2010; Xiao, 1999). In sum, it is necessary to analyze the social support network of "ant tribe". 
The main purpose of the current study is to analyze the social support network of "ant tribe" and propose some effective ways to improve their living status accordingly. Social support network sheds light on the social integration of "ant tribe" so that we could also understand how do they participate in social interactions. With the help of social network analysis, we could have an in-depth understanding of social support network (Liu, 2004; Scott, 2011; Xiao, 1999). By using the network survey data from a group of "ant tribe" in a typical "ant tribe" community in Beijing, we plan to conduct the social network analysis, and compare their network structure with other social groups especially those vulnerable groups.

The current study aims to contribute to the existing literature in a couple of ways. Firstly, we aim to improve the understanding of "ant tribe" by showing the characteristics of their social support network which was neglected by previous literature. Secondly, we aim to figure out how to improve their living status by influencing and altering the structure of their social network. The governance of "ant tribe" is a new issue in society and draws great attention from researchers and policy makers. The current study helps to solve this problem by offering a novel perspective of social support network. Thirdly, the findings on "ant tribe" have implications on other small, weak and disenfranchised groups. "Ant tribe" is not only unique but also similar to other vulnerable groups. So that exploring the social support network of this newly emerged group could identify a new pattern of social interaction. Furthermore, the implications of current study may apply to other similar vulnerable groups.

\section{Method}

\subsection{Subjects and Procedures}

Subjects came from a survey on the low-income college graduates in Xiaoyuehe District, Beijing. We chose that area because it is a typical "ant tribe" community with a large population and high density. We randomly selected two buildings in the community where "ant tribe" lived in. Then we distributed pencil and pen surveys to residents in those two buildings. In this way, we got access to the "ant tribe". In all, 190 questionnaires were distributed and the valid responses came from 179 subjects. The response rate was $94.2 \%$.

\subsection{Measures}

We asked participates to provide demographic information and answer some questions regarding their social support. Specifically, we asked them to generate 5 names by indicating who they turn to in times of life crisis, emotional distress or simply social activities. We used the general social support network which combines the emotional support, instrumental support and social companionship together (Van der Poel, 1993). Emotional support are needed when facing depression or other emotional problem. Instrumental support are typical needs in daily life such as helping with household chores. Social companionship are needed for social activities. The question we asked was "Who would you turn to if you find yourself facing one or more of following situations: feeling depressed; in need of advice on major changes in life, such as changing jobs; having problems in daily life such as getting a cold or stuck in financial rut; planning to see a movie or go shopping. Please nominate five people, and provide their basic information". In this way we got the social support network of "ant tribe".

\subsection{Social Network Analysis}

There are two types of network: ego network and whole network. An ego network starts with a individual ("ego") whom is asked to nominate his or her network contact ("actors"). Ego network has no clear boundary. Except for the "ego", the others usually could not reach other actors in ego network. So that it is mainly used to analyze social ties rather than network structure. By contrast, the whole network, which emphasizes the relationships within groups, has a clear boundary. The structure of whole network influences the efficiency of social support and the information flow within groups. It could also has implications on how to effectively influence the group. In the current study, we collected network data by ego network, and analyzed the characteristics of the giant components by whole network analysis method.

Before analyzing various characteristics of social networks, we transferred the name into the algebraic numbers to get the network. By ignoring the strength and direction of the ties, we ended up with a unweighted and undirected vector $\mathrm{G}(\mathrm{V}, \mathrm{E})$. $\mathrm{V}$ and $\mathrm{E}$ represents a set of the actors and a set of edges respectively. UCINET was used to analyze the network.

\subsubsection{Connectivity}

Connectivity depicts the extent of reachability between actors. The indicators of the network's connectivity include average degree, average distance, density and cluster coefficient. 
Degree refers to the number of neighbors an actor could directly connect to, as is denoted by $d$. Average degree is the mean value of all the degrees in the network. The distance between two actors is the length of the shortest path between them, which means the number of edges an actor need to cross to reach another actor. Distance is denoted by $d(i, j)$. Average distance refers to the mean of distances between all the actors in the network and the formula is shown below:

$$
L=\frac{1}{n} \sum_{i=1}^{n} \sum_{j \neq i} \frac{d(i, j)}{n-1}
$$

Density depicts the extent of closeness among the actors and is defined as the proportion of the actual connections to potential connections. Clustering coefficient refers to the possibility of connection between two actors when they are both connected to another actor, indicating the stability of relationship between members in the network. The greater the clustering coefficient is, the more stable the relationship is.

\subsubsection{Centrality and Centralization}

Two types of indicators are used to describe the position of actors in network: centrality and centralization. Centrality is a micro-level indicator, which reflects the status and influence of actors in the network. While centralization is a macro-level indicator which reflects the distribution of centrality in network. Three kinds of indicators are often used to depict the centrality.

(1) Degree centrality refers to the degree of the focal actor. It implies that the more ties an actor has, the more influence she/he may have.

(2) Betweenness centrality refers to the extent to which an actor could connect with others by lying along the shortest path between two other actors. It demonstrate the fact that the ability to make connections reflects the status and power in a social network. The formula to calculate betweenness centrality is shown as followed:

$$
\mathrm{b}_{k}=\sum_{i, j} \frac{g_{i k j}}{g i j}
$$

(3) Closeness centrality depicts the distance of an actor to reach all others in the network. It implies that the farer from others, the less favored is that actor's position.

\subsubsection{Cluster Analysis}

In many social support network, cluster or community is ubiquitous (Liu, 2004). Cluster or community refers to a group of actors with dense internal connections and sparse external connections. In 2004, Newman and Girvan proposed Modularity index Q, which has been widely used in clustering social network. The higher the Q value is, the more appropriate the division of a subgroup is. It's widely accepted that when $\mathrm{Q}$ is larger than 0.3 , it means that there is a clear cluster structure (Newman \& Girvan, 2004).

\section{Result}

\subsection{Basic Characteristics of "Ant Tribe"}

Before analyzing the social support network of "ant tribe", we took a look at the basis characteristics of this unique group. The demographic information is shown in Table 1. 
Table 1. The Demographic Information of "Ant Tribe"

\begin{tabular}{|c|c|c|c|c|c|}
\hline Variable & & Building No. 1 & Building No. 2 & Total & Missing \\
\hline \multirow{3}{*}{ Gender } & Male & 20 & 110 & 130 & \multirow{2}{*}{1} \\
\hline & Female & 7 & 41 & 48 & \\
\hline & $18 \sim 23$ & 22 & 127 & 149 & \multirow{3}{*}{1} \\
\hline \multirow[t]{2}{*}{ Age } & $24 \sim 35$ & 6 & 23 & 29 & \\
\hline & $>35$ & 0 & 0 & 0 & \\
\hline \multirow{2}{*}{$\begin{array}{l}\text { Beijing registered } \\
\text { permanent residence }\end{array}$} & Yes & 2 & 2 & 4 & \multirow{2}{*}{1} \\
\hline & No & 26 & 148 & 174 & \\
\hline \multirow{2}{*}{$\begin{array}{l}\text { Household registration } \\
\text { (hukou) }\end{array}$} & $\begin{array}{l}\text { Non-agricultural } \\
\text { registered }\end{array}$ & 13 & 50 & 63 & \multirow[b]{2}{*}{1} \\
\hline & $\begin{array}{l}\text { Agricultural } \\
\text { registered }\end{array}$ & 15 & 100 & 115 & \\
\hline \multirow{3}{*}{ Marital status } & Single & 28 & 146 & 174 & \multirow{2}{*}{0} \\
\hline & Married & 0 & 5 & 5 & \\
\hline & Tier-1 university & 2 & 24 & 26 & \multirow{4}{*}{3} \\
\hline \multirow{3}{*}{ Education } & Tier-2 university & 4 & 32 & 36 & \\
\hline & Tier-3 university & 7 & 32 & 39 & \\
\hline & 2-3 year college & 15 & 60 & 75 & \\
\hline \multirow{5}{*}{ Monthly income (RMB) } & $\leq 1000$ & 2 & 17 & 19 & \multirow{5}{*}{4} \\
\hline & $1001 \sim 2000$ & 6 & 60 & 66 & \\
\hline & $2001 \sim 3000$ & 11 & 44 & 55 & \\
\hline & $3001 \sim 5000$ & 8 & 24 & 32 & \\
\hline & $>5000$ & 1 & 2 & 3 & \\
\hline \multirow{3}{*}{$\begin{array}{l}\text { Length of residence in } \\
\text { Beijing (yrs.) }\end{array}$} & $<1$ & 15 & 111 & 126 & \multirow{3}{*}{2} \\
\hline & $2 \sim 5$ & 6 & 26 & 32 & \\
\hline & $>5$ & 5 & 7 & 12 & \\
\hline Total & & 28 & 151 & 179 & 0 \\
\hline
\end{tabular}

As is shown in Table 1, the sample is representative of "ant tribe" population considering gender, age and other demographic characteristics (Lian, 2009). Most of them were male university graduates that aged between 18 to 23 years old. They usually came from rural area and were new to Beijing (length of residence was less than 1 year). Most of them earned a low income which was less than RMB 5000 per month.

\subsection{An Overview of the Network Structure}

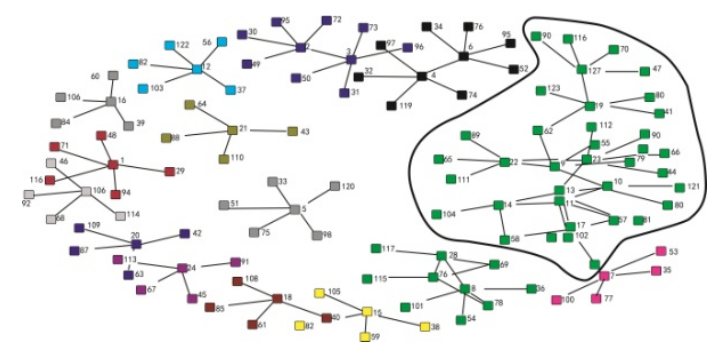

(a)

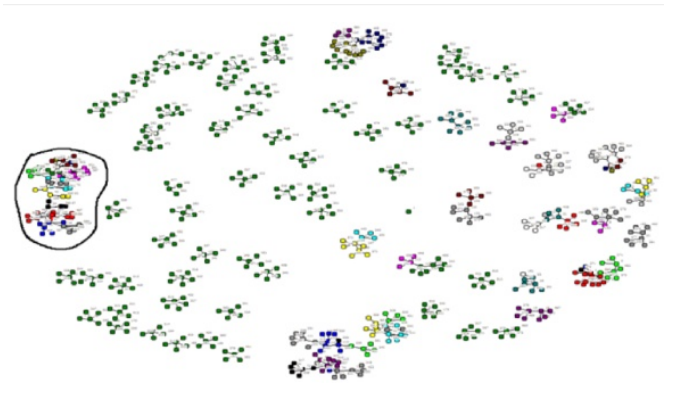

(b)

Figure 1. Social Support Network of Building No. 1 (a) and No. 2 (b) 
Table 2. Indicators of Connectivity

\begin{tabular}{lcccccc}
\hline Network & Actor & Edge & $\begin{array}{c}\text { Average } \\
\text { degree }\end{array}$ & $\begin{array}{c}\text { Average } \\
\text { distance }\end{array}$ & Density & $\begin{array}{c}\text { Average Clustering } \\
\text { Coefficient }\end{array}$ \\
\hline Building No. 1 & 123 & 116 & 1.886 & - & 0.015 & 0.059 \\
Building No. 2 & 620 & 598 & 1.929 & - & 0.003 & 0.112 \\
Giant component of Building 1 & 35 & 39 & 2.229 & 3.859 & 0.066 & 0.057 \\
Giant component of Building 2 & 65 & 74 & 2.277 & 5.891 & 0.036 & 0.070 \\
\hline
\end{tabular}

The networks are shown in Figure 1 and Table 2. In social support network of building No. 1 (Figure 1-a), there were 28 "ant tribe" members and 95 supporters. They constituted a social support network with 123 actors and 116 edges, along with an average degree of 1.886. While in network of building No. 2 (Figure 1-b), there were 151 "ant tribe" members and 469 supporters. They constituted a social support network with 620 actors and 598 edges, along with an average degree of 1.929. The value of average degree was similar to that of migrant workers (average degree $=$ 1.728 ) and urban residents (average degree $=2.550)$ that live in poverty in Tianjing (Z. P. He \& Li, 2009; Jin, Ren, Ren, \& Yue, 2009). The average clustering coefficients of "ant tribe" social support network were quite small (0.059 and 0.112 in each building), indicating the instability of the "ant tribe" network.

As shown in Figure 1, each network had many small components ranging from 4 to 10 people. The components are part of network that is connected within but disconnected from other parts of network. In the social support network of "ant tribe", the components usually consisted of several "ants" and their supporters with an average degree smaller than 2. In reality, the supportive relationships even didn't exist among roommates. The density of building No. 1 and building No. 2 was 0.015 and 0.003 respectively. By contrast, the density of social support networks ranged from 0.239 to 0.723 in a village from Guizhou Province, China (Wang, Zhang, Ma, \& Su, 2008). We could conclude that the connections between "ants" are extremely weak.

\subsection{The Analysis on Giant Component}

Each of the two networks had several components, and the giant components in each network were circled in Figure 1. The giant components could represent the connected relationships among "ant tribe". So that we further analyzed the characteristics of the giant component in each building (shown in Figure 2).

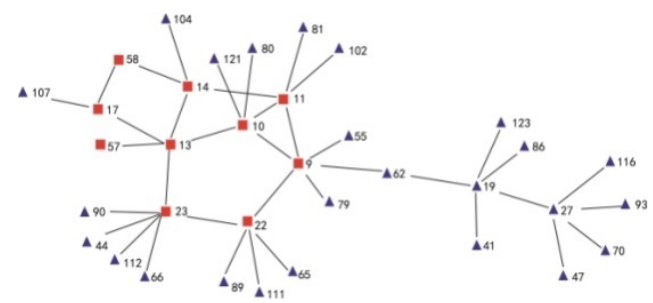

(a)

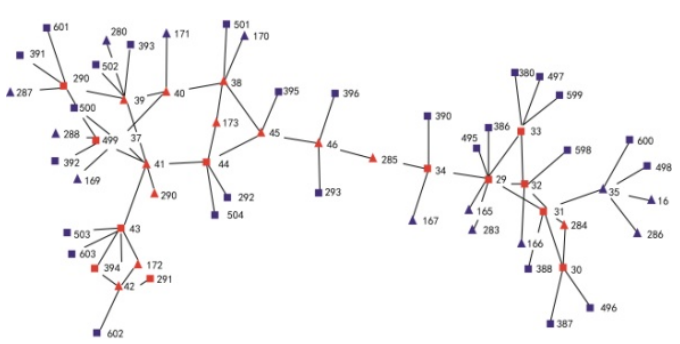

(b)

Figure 2.A. The Giant Component of Building No. 1 (a) and Building No. 2 (b)

As is shown in Table 2, the average distance of those two components was 3.859 and 5.891 respectively, indicating a quite weak connectivity. It means that an actor need an average of 3 to 6 linkers to get in contact with another actor. The density of the those two component was merely 0.066 and 0.036 respectively, which was quite small compared with that of other residents in China (Liu, 2006; Wang et al., 2008). The average clustering coefficient of building No. 2 was bigger than that of building No. 1, indicating a relative better stability. 
Table 3. The Centrality of Giant Component in the "Ant Tribe" Social Support Network

\begin{tabular}{lcccc}
\hline $\begin{array}{l}\text { Building } \\
\text { No. }\end{array}$ & Actor No. & $\begin{array}{c}\text { Degree } \\
\text { centrality }\end{array}$ & $\begin{array}{c}\text { Bewtweenness } \\
\text { centrality }\end{array}$ & $\begin{array}{c}\text { Closeness } \\
\text { centrality }\end{array}$ \\
\hline & 9 & 0.177 & 0.405 & 0.569 \\
Building & 10 & 0.147 & 0.362 & 0.226 \\
No. 1 & 11 & 0.147 & 0.340 & 0.202 \\
& 13 & 0.147 & 0.337 & 0.245 \\
& 14 & 0.118 & 0.306 & 0.122 \\
& 17 & 0.118 & 0.264 & 0.070 \\
& Centralization & 0.118 & 0.497 & 0.286 \\
Building & 29 & 0.125 & 0.205 & 0.519 \\
No. 2 & 43 & 0.109 & 0.191 & 0.204 \\
& 41 & 0.094 & 0.224 & 0.422 \\
& 31 & 0.078 & 0.180 & 0.260 \\
& 38 & 0.078 & 0.220 & 0.200 \\
& 45 & 0.063 & 0.242 & 0.529 \\
& Centralization & 0.092 & 0.460 & 0.141 \\
\hline
\end{tabular}

The centrality of the influential actors and the centralization are shown in Table 3 . It is shown that, \#9, \#10, \#11, \#13, $\# 14$, \#17 were 6 most influential actors in Building 1, and \#29, \#43, \#41, \#31, \#38, \#45 were 6 most influential actors in Building 2. We conducted a further investigation into the characteristics of those influential actors. We found that, they have median monthly income (RMB 2000 - 3000). It seems that economic factor is a potential reason to explain their high status in network.

Table 4. The Community Structure of the Giant Component in Each Building

\begin{tabular}{lcllc}
\hline & \multicolumn{2}{c}{ Building No. 1} & & \multicolumn{2}{c}{ Building No. 2} \\
\cline { 1 - 2 } \cline { 5 - 5 } Subgroup & \multicolumn{1}{c}{ Actor No. } & & Subgroup & Actor No. \\
\hline 1 & 1314175758104107 & & 1 & 3346166285293389396497599 \\
2 & 9194155627986 & & 2 & 303135168284286387496498600 \\
3 & 226589111123 & & 3 & 293234165167283386390495598 \\
4 & 23446690112 & & 4 & 384445170173292395501504 \\
5 & 27477093116 & & 5 & 363941287289290393499502601 \\
6 & 10118081102121 & & 6 & 3740169171288391392500 \\
& $\#$ & & 7 & 4243172291388394503602603 \\
\hline
\end{tabular}

In Figure 1, we found many externally isolated groups which were closely connected within. With respect to the giant component, it can also be divided into a number of subgroups. As shown in Table 4, there were a large number of subgroups in "ant tribe" network. Specifically, the Q value reached the peak $(0.625)$ when the giant component was divided into 6 subgroups in Building No. 1. In building No. 2, the Q value reached the peak $(0.721)$ when the giant component was divided into 7 subgroups. It implied that there were many small subgroups in the "ant tribe" network. The members in subgroups have frequent and strong connections. They offer help, share information, and keep intensive communication in the group, but they have few contacts with members in other groups. That's why no large cluster had dominant influence in the whole network.

\section{Conclusion and Discussion}

The purpose of the present study was to enhance researchers' understanding of "ant tribe" in the perspective of social support network. Even though previous studies have shown that "ant tribe" is suffering from limited social capital and poor social integration (Lian, 2009), it is still unclear how to solve the problems. Social support network could reflect the degree to which they get involved in society. In the perspective of social support network, it is possible to demonstrate the social integration of "ant tribe" and figure out ways to change their status quo. With the survey data from a typical "ant tribe" community in Beijing, we described the basic characteristics of "ant tribe". In contrast with their high education level, they had low income and bad living condition and tended to live as a group. Their social support network had weak connectivity and unstable structure. Large numbers of clusters existed in the network. 
Besides, some key actors played important roles in it.

The findings of this study has practical implication for policy makers. The weak network connectivity of "ant tribe" is partially due to their independent life circles which merely overlap. Thus, an actor has his or her own career, friends and relationships, and it is unnecessary for them to make connection with other "ant tribe" members. As a result, the assistance mainly come from relatives, schoolmates and colleagues. However, we can influence the key persons to establish extensive connections and break the boundaries between subgroups, so as to promote the flow of information and resources among "ants". It is also possible to create event based connections by holding training and other social activities. Those activities are helpful for their skill development as well.

Besides, the social support network of "ant tribe" adds knowledge to the study on social network of vulnerable group as it is a newly emerged group which differs from other groups. Apart from peasantries, migrant workers and laid-off personnel from state-owned enterprises, "ant tribe" is considered to be a newly emerged vulnerable group emerges in China. While researchers have paid less attention on "ant tribe" compared with that on other vulnerable groups (Gui, Berry, \& Zheng, 2012). As a result, we have little knowledge about this unique group. Among those four vulnerable groups, researchers usually compare "ant tribe" with migrant workers as they are all internal migrants (Bian \& Zhang, 2013). Researchers pointed out that a big difference between those two groups was in terms of educational level (Lian, 2009). The current study further revealed that "ant tribe" was different from migrant workers as they had unique social support network. Migrant workers usually migrate with their previous social relationships such as friends and relatives that come from the same village, city or province (laoxiang) (Qiu et al., 2011). By contrast, "ants" leave their previous relationships and migrate solely to big cities, so that "ants" are relatively independent from other "ant tribe" members even though they live together. Compared with "ant tribe", the social interaction among migrant workers is more intense and stronger and social support usually derive from within (Li, Yang, Ren, \& Jin, 2007).

Furthermore, the implications of the current study could apply to other vulnerable groups as "ant tribe" share some similarities with others. For example, just like migrant workers, most of "ants" come from rural areas and leave their hometowns to chase dreams in big cities. As a result, the social support network of both "ant tribe" and migrant workers are small and unstable. Besides, a lot of clusters and key actors (structural holes) exist both among "ant tribe" and migrant workers (Y. K. Ren, Li, Du, \& Feldman, 2008). Thus, breaking the boundaries of inner clusters, enlarging the size of social support network and influencing the key actors are potentially effective ways to improve the status quo of those vulnerable groups.

\section{Acknowledgement}

This study was supported by MOE (Ministry of Education in China) Youth Fund Project of Humanities and Social Sciences (Project No.11YJC840006) and National Social Science Foundation of China (Grant No. 14BSH024). We wish to thank Prof. Zengru Di for his insightful suggestions and advices.

\section{References}

Bian, J., \& Zhang, J. (2013). The communication image construction of the "ant group" and its motivation. Chongqing Social Sciences, 5, 64-68.

Chan, W. K., \& Lu, S. (2011). Graduate unemployment and the emergence of "ant tribe": A social policy perspective. Journal of Public Administration, 3, 146-171.

Gottlieb, B. H., \& Bergen, A. E. (2010). Social support concepts and measures. Journal of Psychosomatic Research, 69(5), 511-520. http://dx.doi.org/10.1016/j.jpsychores.2009.10.001

Gu, C. L., \& Sheng, M. J. (2012). Beijing's ant tribe: a case study of Tangjialing. Human Geography, 27(5), 20-24.

Gui, Y., Berry, J. W., \& Zheng, Y. (2012). Migrant worker acculturation in China. International Journal of Intercultural Relations, 36(4), 598-610. http://dx.doi.org/10.1016/j.ijintrel.2011.11.007

Han, L. (2011). The social cohesion of low-income university graduates. Journal of Capital Normal University (Social Sciences Edition), 5, 143-146.

He, Y., \& Mai, Y. (2015). Higher education expansion in China and the "ant tribe" problem. Higher Education Policy, 28(3), 333-352. http://dx.doi.org/10.1057/hep.2014.14

He, Z. P. (2011). The influence of social support networks on the poor's physical and mental health in urban area. Psychology Science, 34(5), 1144-1150. 
He, Z. P., \& Li, H. Z. (2009). Social support network of urban poverty-stricken population: Take Tianjing as an example. Journal of Tianjin Normal University (Social Science), 5, 33-37.

Jin, X. Y., Ren, F., Ren, Y. K., \& Yue, Z. S. (2009). Social networks and rural migrant workers' first marriage: From gender perspective. Population Journal, 4, 23-33.

Li, S. Z., Yang, X. S., Ren, Y. K., \& Jin, X. Y. (2007). Social network of rural-urban migrants and their occupation stratum and income: Findings from survey in Shenzhen. Modern Economic Science, 29(1), 25-33.

Lian, S. (2009). "Ant tribe": A report on villages inhabited by low-income university graduates. Guangxi: Guangxi Normal University Press.

Lian, S. (2011). Ant Tribe II. Beijing: CITIC Press.

Liu, J. (2004). An introduction to social network analysis. Beijing: Social Sciences Academic Press (China).

Liu, J. (2006). A Whole Network Approach to the Study of the Social Support Network in Village "Fa". Society, 26(3), 69-80.

Newman, M. E., \& Girvan, M. (2004). Finding and evaluating community structure in networks. Physical Review E, 69(2), 69-85. http://dx.doi.org/10.1103/PhysRevE.69.026113

Pan, C. (2010). Annual report on the development of Chinese talents (2010). Beijing: Social Sciences Academic Press (China).

Qiu, P., Caine, E., Yang, Y., Chen, Q., Li, J., \& Ma, X. (2011). Depression and associated factors in internal migrant workers in China. Journal of Affective Disorders, 134(1), 198-207. http://dx.doi.org/10.1016/j.jad.2011.05.043

Ren, S., Zhu, Y., \& Warner, M. (2011). Human resources, higher education reform and employment opportunities for university graduates in the People's Republic of China. The International Journal of Human Resource Management, 22(16), 3429-3446. http://dx.doi.org/10.1080/09585192.2011.586871

Ren, Y. K., Li, S. Z., Du, H. F., \& Feldman, M. W. (2008). Analysis of rural-urban migrants' social network structure based on exponential random graph model. Journal of Xi'an Jiaotong University (Social Science), 28(5), 44-62.

Scott, J. (2011). The SAGE handbook of social network analysis (3rd ed.). London: Sage. http://dx.doi.org/10.4135/9781446294413.n2

Van der Poel, M. G. (1993). Delineating personal support networks. Social Networks, 15(1), 49-70. http://dx.doi.org/10.1016/0378-8733(93)90021-C

Wang, H., Zhang, L., Ma, J. D., \& Su, J. Y. (2008). Analysis of whole social network in health risk management in poor rural areas: A case study in one village of Guizhou Province. Chinse Health Economics, 27(12), 31-34.

Wright, K. B., Rosenberg, J., Egbert, N., Ploeger, N. A., Bernard, D. R., \& King, S. (2013). Communication competence, social support, and depression among college students: a model of facebook and face-to-face support network influence. Journal of Health Communication, 18(1), 41-57. http://dx.doi.org/10.1080/10810730.2012.688250

Xiao, H. (1999). Development of social network analysis The Study of Sociology, 3, 1-11.

Zhang, J. K., Wang, X. R., \& Wu, L. f. (2012). The PPP model of subsidized houses for the "ant tribe" in China. Journal of Southeast University (Philosophy and Social Science), 14(2), 41-46.

Zhang, X. (2013). China's" Ant Tribe" Present Social Survival Situation and Personal Financial Advice. Asian Social Science, 9(2), 24-35. http://dx.doi.org/10.5539/ass.v9n2p24 